\title{
Uma questão de perfil: Análise Enunciativa Multimodal de vídeos para avaliar o potencial da Gamificação personalizada em sala de aula
}

\author{
Silvana Silva* \\ Arthur Marques de Oliveira"
}

\section{Resumo}

O presente trabalho configura-se como uma proposta de análise e aplicação da gamificação personalizada e apresenta os resultados de uma pesquisa e a viabilidade de estratégias de Gamificação em AVAs (Ambientes Virtuais de Aprendizagem), na disciplina de Produção de Textos do curso de Administração da Universidade Federal do Rio Grande do Sul (UFRGS). O objetivo deste estudo é propor e aplicar um construto teórico-metodológico pensando uma nova proposta: refletir sobre os diferentes perfis psicológicos dos estudantes no ensino a distância (EaD), tendo como base estratégias da Gamificação sob a ótica da Teoria da Enunciação de Émile Benveniste. Visando alcançar esse potencial, a metodologia propõe perfilar e analisar trabalhos desenvolvidos de forma presencial e $\mathrm{EaD}$, realizados no segundo semestre de 2019. Nossa Análise Enunciativa Multimodal sugere que quanto maior o uso de suportes multimodais dentro de uma situação de discurso melhor o locutor conseguirá atingir e evocar o alocutário.

Palavras-chave: Gamificação Personalizada; Teoria da Enunciação; Análise Multimodal Enunciativa; Perfis psicológicos.

\section{Primeiras palavras}

Dentre as possibilidades pedagógicas existentes capazes de viabilizar e estimular maior engajamentos e interação entre estudantes está a gamificação, que se refere à utilização de mecanismos de jogos para a resolução de problemas e para a motivação e o engajamento de um determinado público. Gamificação

\footnotetext{
* Doutora em Estudos da Linguagem - UFRGS. Professora Adjunta do Instituto de Letras - UFRGS. E-mail: ssilvana2011@gmail.com

** Graduando em Letras (UFRGS). E-mail: arthubp2@gmail. com
}

Data de submissão: dez. 2020 - Data de aceite: mar. 2021 http://dx.doi.org/10.5335/rdes.v17i01.11110 
no contexto educacional, de acordo com Vianna (2013, p. 9), é "um termo em inglês, sem tradução ou equivalente imediato em português, que se refere ao uso de jogos em atividades diferentes de entretenimento puro". O termo "gamificação" é comumente utilizado para expressar o uso de elementos de jogos (enredo, pontuação e ranking) em contextos que não são de jogos (ambiente de aprendizagem) para motivar ou influenciar as pessoas a realizarem uma determinada atividade (KAPP, 2012).

Dito isso, é importante ressaltar que este trabalho se caracteriza como um desdobramento de um projeto que ocorreu no primeiro semestre de 2019 que também tratava sobre gamificação e engajamento no ensino superior, mas sem refletir previamente sobre os perfis dos estudantes-jogadores e suas respectivas atividades personalizadas. Silva (2013) e Oliveira e Silva $(2018,2020)$ mostram que é necessário elaborar e fazer uso de metodologias e recursos pedagógicos mais novos e sofisticados, pensando no contexto em que os alunos estão inseridos, bem como no fomento à produção de conhecimentos, explorando a aprendizagem significativa (David Ausubel, 1918-2008), a perspectiva da autonomia (Paulo Freire, 1921-1997) e ferramentas relacionadas à gamificação, de modo a incrementar e munir os estudantes de senso crítico e colaborativo.

Desse modo, optamos por trabalhar com a gamificação, pois "os jogos moti- vam, de diferentes maneiras, a avançar em suas etapas adquirindo recompensas à medida que os desafios são superados. Eles ensinam, inspiram e envolvem de uma maneira que a sociedade não consegue fazer" (MCGONIGAL, 2012, p. 15). Concomitante a isso, segundo Gee (2009), os jogos são ferramentas que motivam e engajam seus usuários de modo que fiquem por horas em uma tarefa, com o fim de atingir um objetivo. Alguns dos princípios de aprendizagem que os jogos desenvolvem são: identidade, interação, produção, riscos, problemas, desafios e consolidação. No que tange à pesquisa linguística, será feito o uso de alguns conceitos da Teoria da Enunciação, partindo de uma perspectiva benvenistiana tendo como objetivo analisar as situações de discurso, tendo como base os vídeos elaborados pelos estudantes.

Tendo como base que Oliveira e Silva (2020) já trabalharam com gamificação, mas com o objetivo mais focado na proposta de sequências didáticas gamificadas. Cabe citar aqui as considerações encontradas em seu estudo:

[...] em nosso ponto de vista, que a gamificação aplicada foi considerada algo positivo para o processo de ensino-aprendizagem dos estudantes. Entretanto, foram constatados também dois comentários de exclusão, divididos da seguinte forma: um de exclusão direta e um de exclusão indireta. Isso nos mostra que para alguns estudantes-jogadores a gamificação poderia ter sido melhor; $\mathrm{e}$ é através dessas críticas que essa metodologia poderá ser aprimorada (OLIVEIRA; SILVA, 2020, p. 15). 
Entretanto, os mesmos ressaltam que, por meio desses resultados, foi possível verificar que seria necessário aprofundar mais a pesquisa tanto em termos de análise de perfil e dados quanto na discussão e conceitualização da relação entre a gamificação personalizada, diferentes perfis e atividades personalizadas com base nesses perfis.

\section{Gamificação personalizada e perfis}

Acreditamos ser necessário explicar o que é a gamificação personalizada e como ela está intrinsicamente relacionada aos diferentes tipos de perfis psicológicos afinal, esse é um dos grandes diferenciais desta pesquisa. De acordo com Andrade (2018), as aplicações práticas de gamificação no ensino ainda são bastante escassas, por isso, o trabalho de Monterrat, Lavoué e George (2017) pode ser considerado o primeiro a classificar perfis e experimentar aplicação da gamificação personalizada. A gamificação personalizada pode ser definida como: "a adequação dos elementos apresentados aos usuários é realizada pelo sistema" (ANDRADE, 2018, p. 86). Com base na descrição de gamificação personalizada trazida anteriormente, concordamos com Andrade (2018), entretanto, acreditamos ser importante ressignificar esse conceito para dentro de nossa realidade. Dito isso, assumimos que a gamificação per- sonalizada é a escolha e adequação dos elementos da proposta didática com base na sua classificação de perfil do jogador.

Nesse ponto da pesquisa, perfis e gamificação personalizada se unem, pois é com base nos perfis extraídos dos questionários que foi possível pensar e elaborar atividades pedagógicas diferentes para cada tipo de perfil psicológico. Oliveira e Silva (2020), após a aplicação de um questionário de tipologia com base no trabalho de Andrade (2018), classificaram e dividiram três tipos de perfis: Socializadores (Socialites), Conquistadores (Achievers) e Customizadores (Customizers). Os Socializadores estão interessados no contato com as pessoas e em socializar com outros jogadores. Já os Conquistadores são movidos por objetivos no jogo para se destacar dos outros jogadores, geralmente através da acumulação de pontos; serão atraídos por um inventário de badges ou troféus, por exemplo. Por fim, os Customizadores são conduzidos pela vontade de descobrir o máximo possível sobre o tema proposto. Convidamos quem nos lê a percorrer um caminho cuja primeira parada é uma singela e informativa contextualização sobre gamificação e gamificação personalizada. Em seguida, será explicado como os diferentes perfis psicológicos de motivação podem influenciar a personalização de uma sequência didática. Feito isso, será possível explicar como enunciação e gamificação personalizada 
se conversam e explorar a questão da multimodalidade, presente nas relações interlocutivas e subjetividade dos estudantes. No decorrer dessa jornada, também iremos trazer uma nova proposta de análise, um construto teórico-metodológico com um olhar enunciativo e multimodal.

\section{A Enunciação e o(s) sentido(s)}

Nas obras Problemas de Linguística Geral I e II (PLGs), Benveniste (2005[1954], 2006[1966]) discute e define, especificamente em seu último artigo intitulado $O$ aparelho formal $d a$ enunciação, a questão da enunciação como um processo. $\mathrm{O}$ autor define enunciação como "colocar em funcionamento a língua por um ato individual de utilização" (BENVENISTE, 2005, p. 82). Posteriormente, FLORES et al. (2009) nos mostram na obra Dicionário de Linguística da Enunciação (DLE) que a noção de enunciação supracitada é uma das mais importantes e conhecidas entre os linguistas. Entretanto, não é suficiente para abarcar suas diversas aplicações e res/significações ao longo de vários anos dissertando sobre o tema.

Acreditamos que seja necessário trazer a forma como Benveniste (2005[1954], 2006[1966]) entendia a enunciação por três vieses, são eles: i) "realização vocal da língua"; ii) "conversão da língua em discurso" iii) como realização individual do exercício da língua "no quadro formal de sua realização". Na presente pesquisa, manteremos o foco no sentido de enunciação no segundo viés, pois acreditamos que seja o mais pertinente para as discussões e análises posteriores das situações de discurso; que conforme Flores et al. (2009, p. 218) é uma "circunstância irrepetível de apropriação da língua que instaura a interlocução e a instância espacial e temporal coextensiva e contemporânea da enunciação".

Nesse aspecto, ao falar de enunciação e suas definições, também se faz necessário falar do(s) sentido(s) que a relação "eu-tu" pode abarcar. Benveniste (2006[1966]) em seu texto Semiologia da lingua propõe duas modalidades/planos de sentido, o semiótico e o semântico. No que tange ao semiótico, chama atenção para o fato de que, de todos os sistemas semióticos, a língua é o único capaz de interpretar os outros e também a própria sociedade (BENVENISTE, 2006, p. 45). Benveniste salienta que o semiótico diz respeito ao modo de significação do signo linguístico e que o constitui como unidade, considerado em relação aos demais signos.

No que refere ao plano semântico, ele é a novidade abarcada por Benveniste (2006[1966]), o qual reconhece a necessidade de um aparelho novo de conceitos e definições para dar conta dessa nova informação. É necessário pensar sobre 
a significância que está atrelada ao discurso. Conforme Benveniste (2006, p. 64): "o semântico (o discurso) deve ser compreendido". O modo semântico traz o conjunto dos referentes e se relaciona com o universo do discurso. O semântico é o "sentido" resultante do encadeamento, da apropriação pela circunstância e da adaptação dos signos entre si, manifestando-se na enunciação.

Em outras palavras, enquanto semiótica, a língua é independente de toda referência, formada de signos, cujo sentido é fechado sobre si. O semântico proposto por Benveniste (2006, p. 43) abarca o pragmático, considerando $o$ exercício da língua e supondo todo aparato enunciativo (locutor, interlocutor e situação). Conforme corrobora Cardoso (1997, p. 73), "a distinção do semiótico e do semântico, instituída por Benveniste, é radical, resultando, na verdade, em duas linguísticas, com a necessidade proclamada pelo autor da elaboração de métodos e conjuntos conceptuais distintos, estreitamente apropriados a seu objeto.".

No que tange a pesquisa linguística, será feito o uso de alguns conceitos da Teoria da Enunciação pela perspectiva benvenistiana tendo como objetivo a análise e classificação das situações de discurso, as interações na comunidade linguística e o conteúdo (vídeos) elaborados pelos estudantes. Devido ao fato do estudo e da classificação de perfis se tratar sobre o comportamento dos estudantes e, por consequência, como eles irão construir seus respectivos trabalhos em cada tarefa da gamificação personalizada, concebemos que dentro desse agir esteja a questão enunciativa também. Afinal, "a enunciação é este colocar em funcionamento língua por meio de um ato individual de utilização" (BENVENISTE, 2005, p. 82).

Além disso, a linguagem fornece o suporte para que o dizer seja articulado e a subjetividade evoca a construção de sentido, o locutor "eu" coloca no mundo sua subjetividade e também evoca para que o alocutário "tu" também o faça. Conforme as seguintes citações: "É na instância de discurso que na qual "eu" designa o locutor que este se enuncia como "sujeito". É, portanto, verdade ao pé da letra que o fundamento da subjetividade está no exercício da língua" (BENVENISTE, 2005, p. 288). Vide Benveniste (2005, p.289): "A linguagem é, pois, a possibilidade da subjetividade, pelo fato de conter sempre as formas linguísticas apropriadas à sua expressão; e o discurso provoca a emergência da subjetividade pelo fato de consistir em estâncias discretas".

\section{A busca pela metodologia}

Tendo como base a perspectiva enunciativa, serão analisadas situações de discurso nas três esferas da enunciação 
propostas por Benveniste (2005, p. 83, grifos nossos): "na enunciação consideraremos, sucessivamente, o próprio ato, as situações em que ele se realiza, os instrumentos de sua realização". Essas três esferas estão mais bem especificadas por Flores (2019). Acreditamos que seja pertinente trazer as definições, conforme as seguintes passagens: a) "Ato: para descrever o ato é necessário situar os interlocutores (locutor e alocutário)" (FLORES, 2019, p. 157); b) Situação: "Situação: é o conjunto de das circunstâncias que inclui a situação de discurso, isto é, as coordenadas de tempo, espaço e pessoa" (FLORES, 2019, p. 157).; c) Instrumentos: "Instrumentos: todos os mecanismos que o locutor utiliza para construir a referência de seu discurso" (FLORES, 2019, p. 159).

A Análise Enunciativa está apresentada da seguinte maneira: o ato será composto em identificar os interlocutores (locutor e alocutário) e a relação "eu/tu" do discurso. Consideramos aqui que o "eu" são os estudantes que estão criando o conteúdo do vídeo, o "tu" é composto pelo professor, monitor e turma tendo em vista que há possibilidade de reversibilidade. Em outras palavras, o locutor: estudantes do grupo que estão fazendo a arguição sobre os artigos e alocutário: professor, os outros estudantes da turma e monitor.

A situação em que os interlocutores estavam envoltos teve como foco explo- rar o sentido construído por eles, o que, nesta pesquisa, envolve um contexto pedagógico, pois o vídeo foi feito como uma proposta de avaliação para os estudantes da turma de Produção de Textos do curso de Administração da Universidade Federal do Rio Grande do Sul (UFRGS) do primeiro semestre de 2019 . O objetivo dessa atividade foi analisar artigos de forma crítica e responder qual artigo está mais bem construído e argumentado. Para isso, eles deveriam elaborar um trabalho diferente, conforme seu grupo previamente perfilado. O grupo dos Conquistadores deveria entregar um trabalho escrito; os Socializadores uma apresentação e os Customizadores, um vídeo.

Destacamos aqui que serão analisados apenas dois grupos que configuram o perfil de Customizadores (grupos rosa e roxo). Realçamos esse detalhe, pois primeiramente só havia um grupo de Conquistadores, ou seja, não seria possível fazer uma análise comparativa. Em segundo lugar, devido à questão legal e à ética da imagem dos estudantes, não foi possível gravar as apresentações feitas pelos Socializadores em sala de aula. Sendo assim, a análise do discurso multimodal das gravações dos vídeos será focada em dois principais aspectos, a fala e os instrumentos de suporte do falante dos grupos supracitados, sem qualquer uso de imagem/gestos dos estudantes. 
Os instrumentos que foram utilizados para construção de sentido dos diferentes tipos de ferramenta didática supracitadas abarcam mecanismos do léxico e da língua que configuram o dizer, como figuras de linguagem, adjetivos, advérbios de intensidade e principalmente a linguagem não verbal que compõe parte da análise multimodal como suporte, como, por exemplo, quadros, imagens e esquemas.

\section{Princípios de Análise Enunciativa Multimodal}

Refletindo sobre as três esferas de análise enunciativa descritas anteriormente e olhando para os dados que foram obtidos na pesquisa, acreditamos, assim como Sinte (2018) que há outra forma que vai ao encontro da ótica enunciativa. A Análise do Discurso Multimodal é um paradigma emergente e muito discutido no campo dos estudos linguísticos. Conforme Sinte (2018, p. 3)

[...] a consideração de fatores não verbais em análises discursivas é bastante recente, mesmo que a literatura sobre o assunto continue a crescer exponencialmente (Bertrand 1999, Kita 2000, Tellier 2005, Kendon 2005, Ferre 2007, Behague 2007, de Saint Georges 2008, Rabatel 2010, Constantin de Chanay e Turbide 2011 Lapaire 2013, Tellier 2016). O papel da Análise do Multimodal assumiu um papel importante ao longo dos anos e linguistas agora reconhecem e estudam as funções, cumprida por gestos, olhar e expressões faciais relacionadas às atividades de fala.
Imersos nesse contexto, cujo gesto assume um papel primordial, e tendo como base a polissemia/plurissignificância da palavra discurso, é necessário dizer que adotamos a seguinte definição do conceito de discurso presente na obra de Flores et al. (2009, p. 84): "definição de discurso: atualização da língua cada vez que alguém assume o lugar do "eu". Nota explicativa: As formas da língua, ao serem assumidas por um sujeito, passam a constituir o discurso. Nesse processo, o valor distintivo próprio da língua passa também a expressar um valor enunciativo.”. Esse discurso, conceitualizado por Flores et al. (2009) ao qual nos referimos é um produto enunciativo, que, de acordo com o texto "A noção de discurso na teoria enunciativa de Émile Benveniste" de Flores e Endruweit (2012) há a presença do referente: a língua empregada para a expressão de uma certa relação com o mundo. Ficando claro, que é o discurso que possibilita essa relação, seja entre locutores, seja entre eles e a referência. Vide Benveniste (2006, p. 84):

Na enunciação, a língua se acha empregada para a expressão de uma certa relação com o mundo. A condição mesma dessa mobilização e dessa apropriação da língua é, para o locutor, a necessidade de referir pelo discurso, e, para o outro, a possibilidade de co-referir identicamente, no consenso pragmático que faz de cada locutor um co-locutor. A referência é parte integrante da enunciação.

Dito isso, é interessante fazer o movimento de aproximar Benveniste (2006) 
de Flores e Endruweit (2012) encontrando a referência como parte integrante da enunciação, o que nos sugere estender essa afirmação para o discurso. Quer dizer, mais do que produto, temos agora uma parte integrante da enunciação.

Análise do Discurso Multimodal, propõe uma combinação entre a linguagem e outros recursos tão presentes na era digital como imagens, símbolos, ações, música, entre outros. Conforme Coletta, (2004, p.168), "o conjunto de gestos, expressões faciais e ações não verbais que acompanhar produções linguísticas "e, por outro lado, gestos autônomos, como sendo "produzido independentemente de uma afirmação linguística". É necessário também ampliar a relação entre o visual/oral e explorar mais a questão dos elementos suportes da fala, conforme corrobora Sinte (2018, p. 9),

[...] eles revelam a estreita relação que existe entre oral e visual (sem levar em conta a dimensão gestual) durante apresentações em colóquios, entre linguística (discurso oral) e icônico (suporte visual).

Tendo como base a Análise Enunciativa, proposta por Flores (2019), a Análise Multimodal, presente em Colletta (2004), e reformulada em Análise do Discurso Multimodal, por Sinte (2018), propomos aqui uma complexidade maior de análise. Uma Análise Enunciativa Multimodal que tenha como foco analisar sob a ótica da enunciação, como o sujeito evoca e coloca sua subjetividade por meio de elementos multimodais. Abaixo um esquema ilustrativo de como a metodologia será aplicada.

Figura 1 - Análise Enunciativa Multimoda

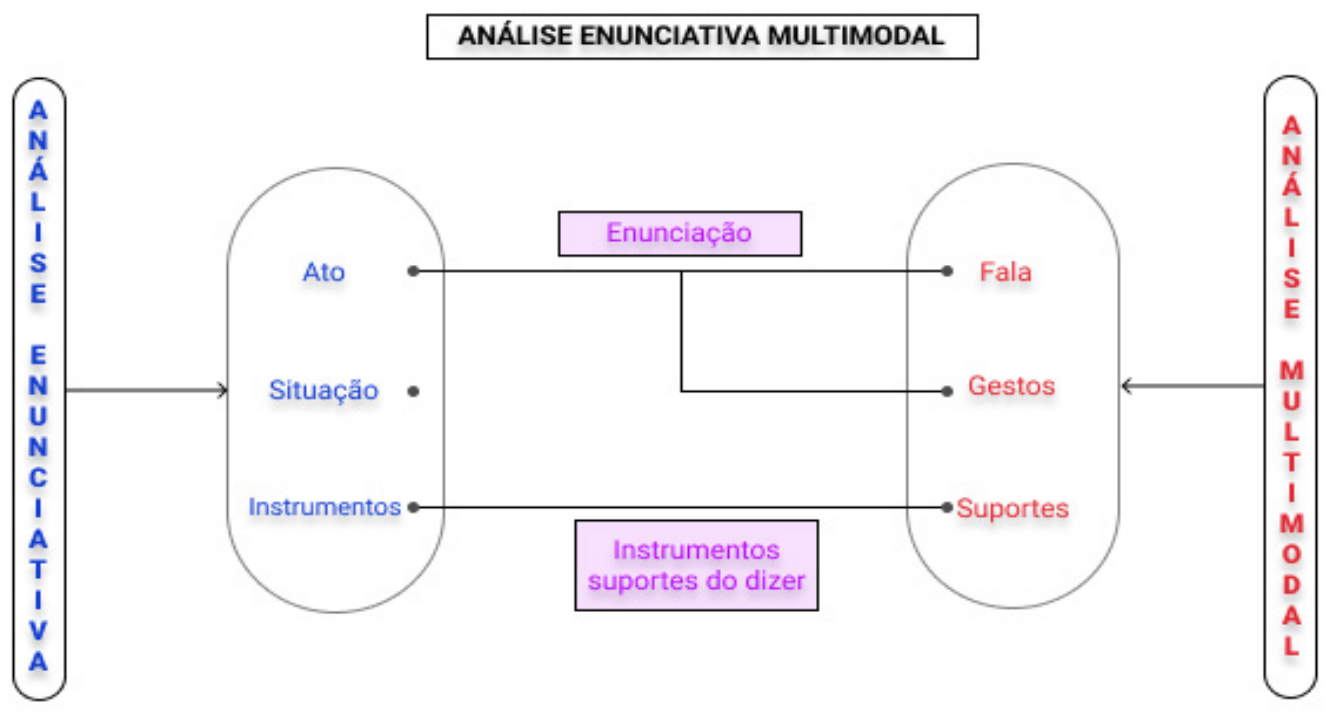

Fonte: elaborado pelos autores, 2020 
O quadro acima retrata/ilustra nosso pensamento de como a Análise Enunciativa e a Análise Multimodal interagem. Por isso, o esquema acima deverá ser lido da seguinte maneira: primeiramente existe a Análise Enunciativa, proposta por Flores (2019), que é composta de ato, situação e instrumentos. No outro lado, a Análise Multimodal, na visão de Colletta (2004), que abarca os elementos de fala, gestualidade e suportes, explicitados por Sinte (2018) compondo a Análise do Discurso Multimodal. Acreditamos que alguns desses elementos se interseccionam da seguinte maneira: os passos e elementos que compõem as análises se complementam, como por exemplo, a fala e a gestualidade podem se corresponder com o ato enunciativo; os elementos de suporte da apresentação na análise multimodal podem compor instrumentos do dizer dentro do contexto enunciativo.

No que tange à análise, ela será subdividida em duas etapas: primeiramente, será apresentada uma tabela classificando e explicando a multimodalidade presente no discurso dos estudantes. Em um segundo momento, será feita uma análise enunciativa das relações dos dois canais do discurso multimodal (fala-F e suportes/apoio de apresentação-S). Dentro desse integrado enunciativo, será feita a análise enunciativa em si, que compreende analisar o ato da enunciação, a situação em que ela ocorre e por fim, os instrumentos no/do dizer utilizados pelos estudantes para enunciar.

\section{Análises Enunciativas Multimodais}

Nesta seção do artigo, serão abarcadas as análises que foram feitas tendo como intendo fazer uma aproximação entre a Análise Enunciativa e a Análise Multimodal, conforme supracitado. O objetivo aqui, é mostrar como cada o grupo rosa e roxo dos Customizadores desenvolveram seus trabalhos visando explicar a multimodalidade presente no discurso dos estudantes através dos quadros comparativos abaixo.

Iniciando pelo Grupo de Customizadores Rosa: um dos integrantes do grupo explica que o artigo eleito como melhor é: "Festa de jabuticaba empreendedorismo feminino no município de Sabará, Minas Gerais”. Após instaurado isso, é apresentado um quadro (S) ilustrando, comparando e subdividindo os argumentos encontrados no artigo. Dessa maneira, o quadro comparativo se torna o principal canal semiótico que apesar de ser um suporte, acaba se tornado primordial para a arguição e entendimento do ponto de vista dos estudantes. 
Tabela 1 - Transcrição Grupo rosa

\begin{tabular}{|c|c|}
\hline F - transcrição & $\begin{array}{l}\text { O artigo a festa de jabuticaba } \\
\text { empreendedorismo feminino } \\
\text { no município de Sabará, Mi- } \\
\text { nas Gerais possui a maior } \\
\text { variedade de tipos de argu- } \\
\text { mentos e também o maior } \\
\text { número de argumentos já que } \\
\text { o texto é mais extenso que } \\
\text { os outros e se utiliza então de } \\
\text { diversos recursos para provar } \\
\text { seus pontos e posições po- } \\
\text { rém, em relação à qualidade } \\
\text { dos argumentos verificamos } \\
\text { que o artigo X, apresenta } \\
\text { argumentos mais bem es- } \\
\text { truturados e embasados, } \\
\text { já que este último apresenta } \\
\text { mais argumentos que fun- } \\
\text { damentam o real e somente } \\
\text { um argumento quase lógico } \\
\text { enquanto o primeiro artigo } \\
\text { comentado apresenta } 31 \text { ar- } \\
\text { gumentos quase lógicos e ne- } \\
\text { nhum que fundamenta o real. }\end{array}$ \\
\hline F - descrição & $\begin{array}{l}\text { Anexo } 2 \text { - Tabela Comparati- } \\
\text { va que colabora para visuali- } \\
\text { zação dos argumentos e sua } \\
\text { distribuição em cada artigo. }\end{array}$ \\
\hline S - Suporte & $\begin{array}{l}\text { Quadro explicativo e compa- } \\
\text { rativo; fala. }\end{array}$ \\
\hline $\mathrm{T}-\mathrm{Te}$ & $\begin{array}{l}\text { Momento crítico da compara- } \\
\text { ção dos artigos ( } 06 \text { min e } 52 \mathrm{~s} \\
\text { até } 07 \text { min e } 34 \mathrm{~s} \text { ) }\end{array}$ \\
\hline
\end{tabular}

Fonte: elaborado pelos autores, 2020

No trabalho dos Customizadores do Grupo rosa, os integrantes do grupo são o locutor "eu" e as pessoas para quem o vídeo se destina, no caso, colegas dos outros grupos, monitor e a professora compõem o alocutário "tu". O ato enunciativo e a relação eu/tu presente no contexto acima apresentado o "eu" está em uma posição de enunciador explicativo-persuasivo e o "tu" se encontra como um interlocutor com possibilidade de inferência pós-explicação, levando em consideração que os vídeos seriam debatidos no fórum da disciplina.

O contexto do trabalho envolve duas perguntas: 1) Qual dos tipos de argumentos vistos na disciplina é o mais presente nos artigos?; e 2) Qual dos artigos está melhor estruturado e argumentado? Justifique sua resposta. Tendo isso como norte, os alunos deveriam avaliar e discutir os artigos trazendo e exemplificando seus argumentos para no final poder embasar sua escolha de melhor artigo.

O grupo faz uso de instrumentos verbais e não-verbais, verbais como mostrar o texto e os exemplos no decorrer do vídeo, e não verbais como a fala e a apresentação de quadros comparativos para justificar sua escolha pelo melhor artigo. No que se refere a construção de sentido, principalmente na fala, conforme está destacado em negrito na Tabela 01 o "eu" se utiliza de elementos do léxico (adjetivos, advérbios de intensidade e grau de substantivos (aumentativo/diminutivo)) e de entonação na fala fazendo referência não necessariamente ao que está sendo dito, mas sim na forma do dizer e incitar o "tu". Com isso, podemos aferir que ele recorre e se apropria da forma para evocar sua enunciação, vide Benveniste (2005, p. 84): "o locutor se apropria do aparelho formal da língua e enuncia sua posição de locutor por meio de índices 
específicos, de um lado, e por meio de procedimentos acessórios, de outro.”.

Tendo como base o aporte teórico, a fala utilizada como suporte a elaboração de esquemas e a apresentação em si, é possível concluir que o Grupo rosa soube articular e justificar seu ponto de vista em relação ao melhor artigo. Dito isso, acreditamos que o uso de elementos lexicais da língua, da linguagem verbal e não verbal de gráficos e o tempo depreendido para fazer com que o leitor/espectador realmente entendesse a linha de raciocínio apresentada na comparação. Dito isso, o Grupo rosa atendeu a proposta da atividade gamificada, tanto no nível do enunciado do trabalho quanto na sua classificação de perfil e ainda conseguiu engajar os estros estudantes para questionamentos sobre seu tema/trabalho. A seguir será abordada a forma como o grupo roxo desenvolveu seu trabalho, esse movimento é necessário para posteriormente fazer a análise da melhor forma tendo como base a multimodalidade presente no discurso dos estudantes.

Grupo de Customizadores Roxo: no início do vídeo um dos integrantes parece para o espectador e começam sua fala, explicando que o artigo eleito como melhor é: "O assédio moral no ambiente de trabalho". Dito isso, o integrante passa a fazer apenas o uso excessivo e único da voz. Nesse vídeo não há quadros ou imagens comparativas, o grupo optou em usar apenas a fala como suporte (S), contudo, essa estratégia pode fazer com que o espectador fadigue e pare de acompanhar a explicação; o que faz com que o interlocutor se parca dentro da linha de raciocínio exposta pelo grupo não estando a favor da explicação comparativa. Nesse grupo, acreditamos que os estudantes não tenham se organizado da melhor forma, tanto as ideias quanto as falas, o que, de acordo com Silva e Della Méa (2018) pode ser visto como um não planejamento prévio à interação comunicativa.

Tabela 2 - Transcrição Grupo roxo

\begin{tabular}{|c|c|}
\hline F - transcrição & $\begin{array}{l}\text { Bom, meu nome é André e } \\
\text { vou responder a segunda } \\
\text { pergunta: qual que é o artigo } \\
\text { mais completo? Bom, res- } \\
\text { pondendo, analisando todos } \\
\text { os artigos o mais completo é } \\
\text { Assédio Moral no ambiente de } \\
\text { trabalho ele é mais comple- } \\
\text { to e informativo, pois possui } \\
\text { os } 8 \text { estágios que mostram a } \\
\text { sua função e clareza a sim- } \\
\text { plicidade contida neles. Com- } \\
\text { preendemos também que sua } \\
\text { linguagem é formal, pois ele } \\
\text { é sofisticado e complexo. } \\
\text { Num primeiro momento é vol- } \\
\text { tado mais para área do direito } \\
\text { do que da administração apre- } \\
\text { sentando regulamento e leis. } \\
\text { É seguindo as etapas nesse } \\
\text { estudo, foram observadas as } \\
\text { formas e espécies de assédio. }\end{array}$ \\
\hline F - descrição & $\begin{array}{l}\text { Anexo } 3 \text { - Visualização do in- } \\
\text { tegrante que representa o gru- } \\
\text { pos na resposta das questões. }\end{array}$ \\
\hline S - Suporte & Fala. \\
\hline T - Tempo & $\begin{array}{l}\text { Momento crítico da compara- } \\
\text { ção dos artigos ( } 07 \text { min e } 54 \mathrm{~s} \\
\text { até } 09 \text { min e } 05 \mathrm{~s} \text { ) }\end{array}$ \\
\hline
\end{tabular}

Fonte: elaborado pelos autores, 2020. 
No trabalho dos Customizadores do Grupo roxo, assim como no Grupo rosa, os integrantes do grupo são o locutor "eu" e as pessoas para quem o vídeo se destina, no caso, colegas dos outros grupos, monitor e a professora compõem o alocutário "tu". O ato enunciativo e a relação "eu/tu" presente no contexto acima apresentado o "eu" está em uma posição de enunciador explicativo e o "tu" se encontra como um interlocutor com possibilidade de inferência pós-explicação, levando em consideração que os vídeos seriam debatidos no fórum da disciplina.

Durante sua apresentação, o grupo faz uso de instrumentos verbais e não-verbais, verbais como escrever algumas classificações de argumentos e os títulos dos artigos, e não verbais como a fala e a escolha e apresentação e um integrante para justificar a escolha do melhor artigo. No que tange a construção de sentido, o "eu" do Grupo roxo, utiliza menos elementos do léxico e passa a dar maior importância para fala. Entretanto, o Grupo roxo faz uso de um roteiro e o "eu" claramente está lendo algo enquanto se comunica com o tu e isso faz com que a referência seja necessariamente ao o que está sendo dito e não a forma do dizer e incitar o tu; em outras palavras: o Grupo roxo não constrói uma situação de discurso tão incisiva com o interlocutor.

Assim como no Grupo rosa, a construção de sentido que o grupo abarca, conforme está destacado em negrito na Tabela 2, o "eu" utiliza de elementos do léxico (adjetivos, advérbios de intensidade e grau de substantivos (aumentativo/ diminutivo)) e de entonação na fala não fazendo referência ao o que está sendo dito, mas sim na forma do dizer e incitar o tu. Entretanto, o Grupo roxo não consegue criar uma situação de discurso incisiva e pertinente com o interlocutor, o que descaracteriza a enunciação. De acordo com Benveniste (2005, p. 87): “o que caracteriza a enunciação é a acentuação da relação discursiva com o parceiro, seja este real ou imaginário, individual ou coletivo".

Levando em consideração a forma como o Grupo roxo trouxe a comparação entre os artigos, a utilização de apenas um suporte, uma certa sistematicidade na fala e o distanciamento do alocutário, é passível de conclusão que a justificativa e explicação do Grupo roxo não ficou clara para o "tu". Isso pode ser corroborado por alguns comentários feitos pelos espectadores no fórum do grupo, como por exemplo: "o primeiro artigo apresentou o argumento do dilema; o terceiro apresentou o da sucessão. Por que vocês escolheram o primeiro artigo como o melhor?". Nesse cenário, o Grupo roxo atendeu parcialmente a proposta da atividade gamificada, e deixando de lado a explicação do enunciado do trabalho. Imerso nessa conjuntura, é indubitável que o Grupo rosa fez uso de 
mais elementos suportes do que o Grupo roxo, deixando mais claro suas razões e justificativas sobre a escolha do melhor artigo. Abaixo uma tabela resumindo quais suportes multimodais cada grupo fez uso:

Tabela 3 - Comparação de elementos Suportes

\begin{tabular}{|l|c|c|}
\hline & $\checkmark$ & $\checkmark$ \\
\hline Fala & $x$ & $\checkmark$ \\
Gestos & $\checkmark$ & $x$ \\
\hline Quadro & $\checkmark$ & $x$ \\
\hline Imagem & $\checkmark$ & \\
\hline
\end{tabular}

Fonte: elaborado pelos autores, 2020

\section{Considerações Finais}

Em virtude da reflexão teórica e das análises apresentadas acima, podemos concluir que a gamificação personalizada, enquanto ferramenta didática, contribui para disseminar e incitar discussões dentro e fora do ambiente virtual. Mais especificamente, no tocante aos resultados das análises, acreditamos que esse tipo de estratégia facilita uma identificação por parte dos estudantes com a proposta de atividade, pois ao desenvolverem o trabalho os estudantes se sentem mais confortáveis com o fazer pedagógico referenciado ao seu perfil. Ainda assim, por meio da mecânica de jogos, a motivação e o engajamento dos indivíduos foram potencializados; além disso, também ocorreram mais interações, o que de certa forma nos surpreen- deu, visto que a disciplina é ofertada para alunos do primeiro semestre.

Ademais, percebemos que a união da abordagem multimodal com a enunciativa nos permitiu investigar e explicitar os modos utilizados pelos estudantes nas interações dos trabalhos. Nota-se também que sua unidade de análise teve como foco o suporte à ação e esse evento comunicativo nos quais os indivíduos se engajam (situações de discurso). Dito isso, também colocamos aqui que ao fazer esse movimento de enunciar e $o$ uso de instrumentos suportes é possível aferir seus modos de comunicar e enunciar. Afinal, para reforçar a importância que há em cada enunciação e situação de discurso, recorremos a Benveniste (2005, p. 83): "antes da enunciação, a língua não é senão possibilidade de língua". Em outras palavras, é somente no/pelo processo de enunciação que o enunciado passa a existir no mundo, tornando-se efêmero e irrepetível.

Por fim, concluímos que a personalização da gamificação ainda está sendo desenvolvida e sofrendo experimentações, por isso, nesta pesquisa, procuramos estabelecer algumas bases para desenvolver e servir de propulsor para avanços na área. Dentro de nosso trabalho, ainda colocamos uma nova perspectiva de análise que une duas teorias de análise já existentes a vistas de incitar novas formas de se discutir e 
aplicar a Teoria da Enunciação com a sociedade e a academia.

\section{A question of profile: Multimodal Enunciative Analysis of video to evaluate the potential of personalized Gamification in classroom}

\section{Abstract}

this paper it's a proposal for the analysis and application personalized gamification and presents the results of a research and the viability of Gamification strategies in VLEs (Virtual Learning Environments), in the discipline Text Production of the Administration course at Federal University of Rio Grande do Sul (UFRGS). The aim of this study is propose and apply a theoretical-methodological construct thinking a new proposal: to reflect on the different psychological profiles of students in Distance Education (DE), based on Gamification strategies from the perspective of Émile Benveniste's Enunciation Theory. Aiming to reach this potential, the methodology proposes to profiler and analyze works developed in person and distance education, carried out in second semester of 2019. Our Enunciative Multimodal Analysis suggests that the greater the use of multimodal supports within a discourse situation the better the announcer will be able to achieve and evoke the interlocutor.

Keywords: Custom Gamification; Teory of Enunciation; Multimodal Enunciative Analysis; Psychological Profiles.

\section{Referências}

ANDRADE, Fernando Roberto Hebeler. Gamificação personalizada baseada no perfil do jogador. 2018. Tese (Doutorado em Ciências de Computação e Matemática Computacional) - Instituto de Ciências Matemáticas e de Computação, Universidade de São Paulo, São Carlos, 2018. Disponível em: < https:// teses.usp.br/teses/disponiveis/55/55134/tde18102018-111511/pt-br.php>. Acesso em: 14 out. 2019.

BENVENISTE, Émile. Problemas de Linguística Geral I. Campinas: Pontes, 2005.

. Problemas de Linguística Geral II. Campinas: Pontes, 2006.

COLLETTA, Jean-Marc. (2004). Le développement de la parole chez l'enfant âgé de 6 à 11 ans. Corps, langage et cognition. Sprimont : P. Mardaga. Disponível em: <https:// www.persee.fr/doc/rfp_0556-7807_2005_ num_151_1_3284>. Acesso em: 02 jan. 2020.

FLORES, Valdir do Nascimento et al. (Orgs). Dicionário de Linguística da Enunciação. São Paulo: Contexto, 2009.

FLORES, Valdir do Nascimento.; ENDRUWEIT, Magali Lopes. A noção de discurso na teoria enunciativa de Émile Benveniste. Revista Moara, n.38, p.196-208, jul./dez., Estudos Linguísticos, 2012. Disponível em: $<$ https://periodicos.ufpa.br/index.php/moara/ article/download/1280/1698>. Acesso em: 12 abr. 2020.

FREIRE, Paulo. Pedagogia da Autonomia. Saberes necessários à prática educativa. 51 . ed. Rio de Janeiro: Paz e Terra, 2015.

OLIVEIRA, Arthur Marques de. SILVA, Silvana. A Pertença do aluno à comunidade linguística da sala de aula: um estudo enunciativo das relações interlocutivas em uma turma de produção textual. Revista de Divulgação Científica em Língua Portuguesa, Linguística e Literatura Ano 14 - n.23, p.313332 - 20 Semestre - 2018 - ISSN 1807-5193. 
Disponível em: <http://www.letramagna.com/ artigos_23/artigo18_23.pdf $>$. Acesso em: 08 set. 2019.

OLIVEIRA. Arthur Marques de; SILVA. Silvana. Um chefão no ensino superior: olhar enunciativo sobre a gamificação no ensino de gêneros textuais. Revista Docência do Ensino Superior, Belo Horizonte, v. 10, p.1-20, 2020.

FLORES, Valdir do Nascimento.; et al. $M a-$ nual de Linguística: semântica, pragmática e enunciação. Petrópolis: Vozes, 2019. v. 1.

SILVA, Silvana. O homem na língua: uma visão antropológica da enunciação para o ensino da escrita. 2013. 222. Tese de Doutorado em Estudos da Linguagem - Programa de Pós-graduação em Letras, Universidade Federal do Rio Grande do Sul, Porto Alegre, 2013.

SILVA, Silvana.; DELLA MÉA, Célia Pelegrini. Avaliação de gêneros orais: critérios em debate. Diálogo das Letras, Pau dos Ferros, v. 7, n. 2, p. 44 - 60, maio/ago. 2018. Disponível em: <http://periodicos.uern.br/index.php/ dialogodasletras/article/view/3205> Acesso em: 20 maio 2020.

VIANNA, Y. et al. Gamification, Inc. São Paulo: MJV Press, 2013.

SINTE. Aurélie. Répéter, redire, reformuler: analyse plurisémiotique de conférences TEDx. Congrès Mondial de Linguistique Française - CMLF 2018. 